\title{
Predictive Factors of Multiple Hospitalizations for Acute Exacerbations of COPD
}

\author{
Ahmed Ben Saad* (D), Nesrine Fahem, Asma Migaou, Saousen Cheikh Mhamed, Samah Joobeur, \\ Naceur Rouatbi
}

Pulmonology Department, Fattouma Bourguiba Teaching Hospital, Monastir, Tunisia

Email: *ahmedbensaad28@yahoo.fr

How to cite this paper: Saad, A.B., Fahem, N., Migaou, A., Mhamed, S.C., Joobeur, S. and Rouatbi, N. (2019) Predictive Factors of Multiple Hospitalizations for Acute Exacerbations of COPD. Open Journal of Respiratory Diseases, 9, 61-74. https://doi.org/10.4236/ojrd.2019.93006

Received: May 20, 2019

Accepted: July 7, 2019

Published: July 10, 2019

Copyright $\odot 2019$ by author(s) and Scientific Research Publishing Inc. This work is licensed under the Creative Commons Attribution International License (CC BY 4.0).

http://creativecommons.org/licenses/by/4.0/

(c) (i) Open Access

\begin{abstract}
Background: Multiple hospitalizations for acute exacerbations of chronic obstructive pulmonary disease (AECOPD) are associated with considerable morbidity and mortality. Objectives: To identify predictive factors of multiples hospitalizations for AECOPD. Methods: This is a retrospective single center study of consecutive patients with COPD hospitalized at the Department of Respiratory Medicine between January 1990 and December 2015. We calculated for each patient the mean number of hospitalizations for AECOPD/year (H/y). We distinguished 2 groups $(\mathrm{G})$ of patients. $\mathrm{G} 1:<2 \mathrm{H} / \mathrm{y}$ and G2: $\geq 2 \mathrm{H} / \mathrm{y}$. Predictors of multiple admissions identified by univariate analysis were included in the multivariate analysis. Results: The study included 1167 COPD patients (mean age $67 \pm 10$ years, 97\% males). Three hundred six (26\%) COPD patients had a mean number of hospitalizations per year $\geq 2$. Multivariate logistic regression analysis demonstrated that an $\mathrm{mMRC} \geq 2$ (Odd ratio [OR] 1.8, 95\% confidence interval [CI] $1.08-2.99, \mathrm{p}=0.022$ ), a low $\mathrm{PaO}_{2}\left(\mathrm{PaO}_{2}\right.$ OR 0.97, 95\% CI $\left.0.95-0.99, \mathrm{p}=0.007\right)$ and frequent exacerbations (OR 2.95, 95\% CI $2.56-3.39, \mathrm{p}<0.001$ ) are independent factors associated with multiple admissions for AECOPD. Conclusions: An mMRC $\geq 2$, a low $\mathrm{PaO}_{2}$ and frequent exacerbations are independently associated with multiple hospitalizations for AECOPD. The identification of these high risk COPD patients will be helpful in the decision of intervention strategies.
\end{abstract}

\section{Keywords}

COPD, Hospitalization, COPD Exacerbation, Risk Factors, Hospital Readmission

\section{Introduction}

Chronic obstructive pulmonary disease (COPD) is a common, preventable and 
treatable disease that is characterized by persistent respiratory symptoms and airflow limitation that is due to airways and/or alveolar abnormalities usually caused by significant exposure to noxious particles or gases [1]. COPD is an important public health challenge since it is responsible for a considerable morbidity and mortality worldwide with a heavy burden on health care resources. It is the fourth leading cause of death in the world and will be the third by 2020 [1]. Exacerbations of COPD are defined as an acute worsening of respiratory symptoms that results in additional therapy [1]. An acute exacerbation (AE) leading to hospitalization is considered as severe exacerbation [1]. Hospital admissions for AECOPD are associated with considerable health-care costs, morbidity and mortality [2]. In fact, the majority of health care expenditure related to COPD arises from hospitalization. Thus, preventing exacerbations and especially hospitalizations is a major component of COPD management strategies. Despite the importance of hospitalization for AECOPD, little is known about the factors related to these events and their recurrence. Indeed, some COPD patients have an increased risk of recurrence of an AECOPD following hospitalization [3]. Readmissions for AECOPD are known to have pejorative consequences [4]. The hospital readmission rate for AECOPD remains high through the world despite improvement in the management of COPD. In some studies, the rate of readmission within one year reached $60 \%$ [5] [6]. The reasons for readmission are not fully clarified. Therefore, establishing the profile of patients who tend to be readmitted by identifying the risk factors of multiple admissions of AECOPD is a core issue. Approximately $10 \%$ to $55 \%$ of readmissions for AECOPD may be preventable [7]. Factors associated with readmission provide important information for health care planning. Reducing readmissions has become a policy target in different countries and an important goal for health-care institutions [7]. Some predictors have been identified [8] [9] and certain strategies have been proposed [10]. But there is not enough evidence at present to recommend standardized approach for this problem [10] [11].

The aim of this study is to identify predictive factors of multiples hospitalizations for AECOPD. We believe that the identification of these factors will be helpful in the decision of intervention strategies, leading to better standards of care and better outcomes for patients.

\section{Methods}

\subsection{Study Design and Subjects}

This is a retrospective single center study of consecutive patients with COPD hospitalized for $\mathrm{AE}$ at the Department of Respiratory Medicine of Fattouma Bourguiba Hospital in Monastir (Tunisia) between January 1990 and December 2015. All the patients had a diagnosis of COPD according to the Global Initiative for Chronic Obstructive Lung Disease (GOLD) guidelines (the presence of a post-bronchodilator forced expiratory volume in 1 second (FEV1)/forced vital capacity $(\mathrm{FVC})<0.7$ in patient with appropriate symptoms and significant ex- 
posures to noxious stimuli) [1]. We defined AECOPD according to GOLD definition as an acute event characterized by a worsening of the patient's respiratory symptoms that is beyond normal day-to-day variations and leads to a change in medication [1]. We defined severe exacerbation as an exacerbation requiring hospital admission and moderate exacerbation as AE requiring treatment with antibiotics and/or short course of oral corticosteroids [1]. Admission was defined as a medical ward stay of greater than $24 \mathrm{~h}$ duration. After the first hospitalization, the included patients had a period of follow-up post-discharge of at least one year. We calculated for each patient the mean number of AE (moderate and severe) per year. We considered also hospitalizations for AECOPD in other hospitals reported by patients during the period of follow-up. We categorized patients according to COPD severity based on FEV1 (GOLD grades 1-4). Potential participants were not included based on the following criteria: hospitalizations for other reasons than AECOPD like community-acquired pneumonia, heart failure, pneumothorax, pulmonary embolism ..., and a co-existing pulmonary disease which may lead to multiple admissions like Asthma-COPD Overlap, suspected underlying malignancy or active pulmonary tuberculosis.

\subsection{Grouping}

We calculated for each patient the mean number of hospitalizations for AECOPD/year (H/y). We distinguished 2 groups (G) of patients. G1: $<2 \mathrm{H} / \mathrm{y}$ and $\mathrm{G} 2: \geq 2 \mathrm{H} / \mathrm{y}$ defining the multiples hospitalization's group.

\subsection{Data Collection}

Data on demographic variables (gender, age, body mass index (BMI)), smoking status, presence of comorbidities, baseline dyspnea grade as defined by modified Medical Research Council (mMRC), number of hospitalization for AECOPD during the follow-up period, number of AECOPD/year (including severe and moderate $\mathrm{AE}$ ), pulmonary function tests (PFT), use of long-term oxygen therapy and medications were collected from medical records. Spirometry and blood gases ware performed in the stable period. FEV1 decline was appreciated for patients having 3 or more spirometries in stable period during follow-up. Data on prognosis (cumulative number of deaths for all-causes and survival rates) were recorded.

No patient consent was required as it is a retrospective study utilizing the COPD database of our department and no specific patient identifiable information was utilized. Patient confidentiality was maintained by de-identification of all data.

\subsection{Statistical Analysis}

Statistical analysis was performed with the Statistical Package for Social Sciences (SPSS) V. 20 for Windows. Categorical variables were expressed in absolute values and proportions. Continuous variables were expressed as mean $\pm \mathrm{SD}$. Means 
were compared using the Student's t-test for independent samples. Proportions between groups were compared using the chi-square test. Factors that were significantly associated to multiple hospitalizations in univariate analysis were included in the multivariate analysis using binary logistic regression, and odds ratios (OR) were calculated. Results were expressed as odd ratios (OR) with 95\% confidence intervals (CI). Difference in the survival rates between the two groups was analyzed with the use of the Kaplan-Meier survival curves, log-rank and Breslow tests. A P value $<0.05$ was considered significant.

\section{Results}

\subsection{Baseline Characteristics of COPD Patients}

A total of 1167 patients fulfilled the eligibility criteria and were included in the study. The clinical characteristics of the COPD patients are presented in Table 1. The mean age of the total sample was $67 \pm 10$ years, with $97 \%$ males and $96 \%$ current or former smokers. The mean FEV1 was $1.16 \pm 0.48(43 \% \pm 16 \%$ of predicted). Patients were followed for a mean period of $4.1 \pm 3$ years. Three hundred six (26\%) COPD patients had a mean number of hospitalizations per year $\geq$ 2 (Figure 1).

Table 1. Baseline characteristics of COPD patients.

\begin{tabular}{|c|c|c|}
\hline & Number/Mean & Frequency \\
\hline N Patients & 1167 & \\
\hline Age & $67 \pm 10$ & \\
\hline Gender (Male) & 1130 & $97 \%$ \\
\hline Smoking (current or former) & 1126 & $96 \%$ \\
\hline Pack years & $61 \pm 28$ & \\
\hline Comorbidities $\geq 1$ & 1010 & $86.5 \%$ \\
\hline $\mathrm{mMRC} \geq 2$ & 748 & $64 \%$ \\
\hline FEV1 (L) & $1.16 \pm 0.48$ & \\
\hline FEV1 (\%) & $43 \pm 16$ & \\
\hline FEV1/FVC (\%) & $57 \pm 10$ & \\
\hline GOLD III/IV & 822 & $70 \%$ \\
\hline $\mathrm{PaO}_{2}(\mathrm{mmHg})$ & $68 \pm 11$ & \\
\hline $\mathrm{PaCO}_{2}(\mathrm{mmHg})$ & $41 \pm 7$ & \\
\hline N AECOPD/year & $2.8 \pm 1.85$ & \\
\hline N H Pulmonary Department/year & $1.22 \pm 0.96$ & \\
\hline $\mathrm{H}$ in ICU & 338 & $29 \%$ \\
\hline Chronic Respiratory Failure & 652 & $55.9 \%$ \\
\hline Home Oxygen & 192 & $16.5 \%$ \\
\hline Follow-up (year) & $4.1 \pm 3$ & \\
\hline
\end{tabular}

N: Number, H: Hospitalization, ICU: Intensive care unit. 


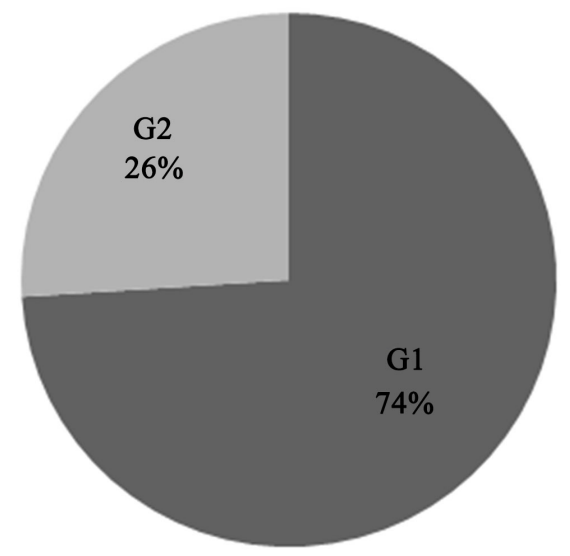

Figure 1. Distribution of COPD patients between the two groups.

\subsection{Impact of Multiple Hospitalizations on Survival Rates of COPD Patients}

Kaplan-Meier-estimated cumulative survival was significantly shorter in G2 than in G1 (Log Rank < 0.001, Breslow: 0.014) with a median overall survival of 48 and 84 months respectively (Figure 2).

\subsection{Univariate Analysis of Risk Factors Associated with Multiple Hospitalizations among COPD Patients}

No significant differences were found between the 2 groups in terms of age, gender, BMI, presence of co-morbidities or smoking status. However, several other variables were significantly associated with multiples hospitalizations in the univariate analysis. Patients with multiple hospitalizations were more likely to be diabetics, had higher mMRC dyspnea scores, an altered respiratory function, a greater number of $\mathrm{AE}$ per year, with more $\mathrm{AE}$ due to pyocyanic, than those with infrequent admissions (Table 2).

\subsection{Multivariate Predictors of Multiple Hospitalizations in COPD Patients}

On multivariate analysis, being a symptomatic COPD patients with $\mathrm{mMRC} \geq 2$ (Odd ratio [OR] 1.8, 95\% confidence interval [CI] $1.08-2.99, \mathrm{p}=0.022$ ), a low $\mathrm{PaO}_{2}\left(\mathrm{PaO}_{2} \mathrm{OR} 0.97,95 \% \mathrm{CI} 0.95-0.99, \mathrm{p}=0.007\right)$ and frequent exacerbations (OR 2.95, 95\% CI $2.56-3.39, \mathrm{p}<0.001$ ), were independently associated with multiple admissions for AE of COPD (Table 3).

\section{Discussion}

Hospitalizations for AECOPD are associated with a poor prognosis. This study aimed to identify the factors associated with multiple hospitalizations for AECOPD. The results suggest that having an $m M R C \geq 2$, a low $\mathrm{PaO}_{2}$ and frequent exacerbations, are independent factors associated with multiple admissions for AE of COPD. 


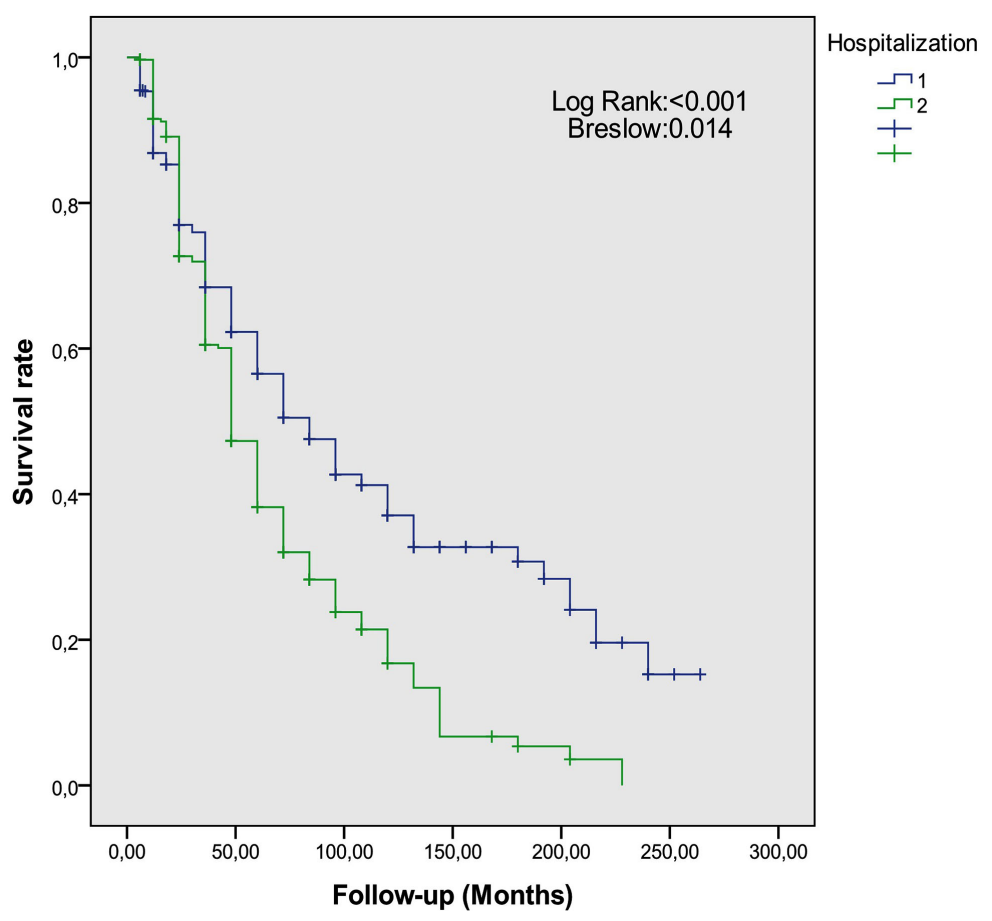

Figure 2. Kaplan-Meier survivor curves for G1 and G2 COPD patients.

Table 2. Univariate predictors of multiple hospitalizations among COPD patients.

\begin{tabular}{|c|c|c|c|}
\hline & $\mathrm{G} 1<2 \mathrm{H} / \mathrm{Y}$ & $\mathrm{G} 2 \geq 2 \mathrm{H} / \mathrm{Y}$ & $\mathrm{P}$ \\
\hline Age (years) & 67.6 & 66.9 & 0.31 \\
\hline Gender (Male,\%) & 96.7 & 97.1 & 0.79 \\
\hline BMI $\left(\mathrm{kg} / \mathrm{m}^{2}\right)$ & 24.04 & 23.83 & 0.61 \\
\hline Comorbidities $\geq 1$ (\%) & 87 & 85.3 & 0.45 \\
\hline Cardiovascular comorbidities (\%) & 38.9 & 44.1 & 0.11 \\
\hline Diabetes & 14.4 & 19.6 & 0.032 \\
\hline \multicolumn{4}{|l|}{ Smoking status: } \\
\hline Current or ex-smokers (\%) & 96.1 & 98.3 & 0.26 \\
\hline $\mathrm{mMRC} \geq 2(\%)$ & 56 & 87 & $<10-3$ \\
\hline FVC (L) & 1.91 & 1.62 & $<10-3$ \\
\hline FEV1 post $\beta 2(\mathrm{~L})$ & 1.24 & 0.97 & $<10-3$ \\
\hline FEV1/FVC post $\beta 2(\%)$ & 58.4 & 54.5 & $<10-3$ \\
\hline Mean FEV1 decline (ml/year) & 56 & 65 & 0.035 \\
\hline $\mathrm{PaO}_{2}(\mathrm{mmHg})$ & 70.2 & 63.5 & $<10-3$ \\
\hline $\mathrm{PaCO}_{2}(\mathrm{mmHg})$ & 40.4 & 43.2 & $<10-3$ \\
\hline $\mathrm{N}$ of AE/year & 2.1 & 4.7 & $<10-3$ \\
\hline AE due to Pyocyanic (\%) & 4 & 15.4 & $<10-3$ \\
\hline Chronic respiratory failure (\%) & 48 & 75 & $<10-3$ \\
\hline
\end{tabular}


Table 3. Multivariate predictors of multiple hospitalizations among COPD patients.

\begin{tabular}{cccc}
\hline & P value & OR & CI (95\%) \\
\hline $\mathrm{mMRC} \geq 2$ & 0.022 & 1.8 & $1.08-2.99$ \\
$\mathrm{PaO}_{2}$ & 0.007 & 0.97 & $0.95-0.99$ \\
$\mathrm{~N} \mathrm{AE} /$ Year & $<10-3$ & 2.95 & $2.56-3.39$ \\
\hline
\end{tabular}

The major strengths of the present study were: a considerable sample size, an acceptable period of follow-up, and the availability of data having allowed to study several parameters related to the severity of the disease. Furthermore, our data were based on records. COPD patients were hospitalized and treated retrospectively before the development of the study. Thus, the retrospective nature of this study has the advantage that there is no bias related to indications of hospitalization or the choice of the ambulatory treatment of AECOPD. Therefore, the results represent the real-life situation in our hospital. On another hand, the choice of one year as a period to identify multiple hospitalizations may allow us to recognize other factors related to multiple admissions not determined in studies with a cut-off period of 30 or 90 days.

Nevertheless, the current study is not without limitations. In fact, since the retrospective character of this research, not all variables could be collected for every patient. Also, our COPD population is characterized by a severe and very severe obstruction with $70 \%$ of patients GOLD 3 or 4 , that could have some implication on the results. We considered the mean number of hospitalizations per year but not the number of rehospitalizations during the year following an index admission for AECOPD. It would be complex to specify in a retrospective study which hospitalization to be considered as an index admission. Consequently, we didn't studied the characteristics of each severe $\mathrm{AE}$ and its impact on the time of readmission. In addition, it is possible that other factors were not included in the final model based on the available data. In fact, to minimize bias in the study, we chose variables that had been systematically, and objectively recorded. Finally, patients included in this study were hospitalized between 1990 and 2015. This is a prolonged period of time during which COPD guidelines and therapeutic choices changed and progressed.

Published data about multiple hospitalizations analyzed several factors that can be associated to readmissions. But there is a lack on the definition of readmission after hospitalization for AECOPD [7]. In fact, readmission may be defined as rehospitalization for AECOPD or it may be due to any other cause. In a large study conducted in the United States, $26 \%$ of readmissions 30 -days post discharge are due to AECOPD and, overall $50 \%$ are due to respiratory-related causes [7]. Also, the majority of rehospitalizations in COPD patients are not respiratory-related [11]. This may lead to confusion if readmissions for AECOPD are compared with all-cause readmissions [11]. Another problem is that there is no standardized definition for multiple admissions or rehospitalization regarding the time to next admission. The latter is varying in publications from early 
readmissions (30-day) to a 2 year period [7].

There is a great discrepancy in the readmission rates of COPD patients in the literature. In the study of Tsui et al., 73\% of COPD patients were readmitted at least once for AECOPD during the year after hospital discharge [12]. A retrospective study carried out in a Hong Kong regional hospital, 59\% of COPD patients had been readmitted at least once by the end of 1 year after discharge from the index admissions [13]. In the latter study, a 24-h emergency department stay was considered as an admission. Garcia Aymerich et al. get $63 \%$ as a rate of readmission during a mean period of follow-up of 1.1 years [5]. A lower rate of $45 \%$ of readmission in one year after discharge was found in the study of Wei et al. [4]. In our study, only $26 \%$ COPD patients had a mean number of hospitalizations per year more than 2. This low rate of rehospitalization in comparison with other published result may be due to the study design and inclusion criteria. For example, the study of Tsui et al. included patients hospitalized in the department of medicine and geriatrics with a population's mean age of $76.7 \pm$ 7.7 (67 years for our population) [12]. Readmission rates are varying according not only to the characteristics of the COPD population but also the considered interval time to readmission. One in three patients hospitalized due to AECOPD was readmitted within 90 days according to an England healthcare commission [14]. In another study, performed at a single centre in the United States, nearly $20 \%$ of patients discharged for AECOPD were readmitted within 30 days [15]. The rate of readmission within 30 days of discharge for AECOPD is about $17 \%$ in Spain [16] and 14\% in the Netherlands [17]. These differences are probably due to the different methodology used in each study.

In the present study, the median overall survival was significantly shorter in G2 than in G1. This is in accordance with several other reports. In a Spanish cohort study, a history of at least two hospitalizations for AECOPD the previous year was independently associated with a higher overall mortality (OR, 7.63; 95\% CI, $3.41-17.05$ with $\mathrm{p}<0.001$ ) [18].

Previous studies of multiple admissions for AECOPD identified a number of risk factors. Readmission is still considered to be avoidable and led to the establishment of a penalty system for readmission within 30 days in the USA [19] [20]. Several predictive factors for multiple admissions of COPD patients have been described, including demographic features (age, sex, race, BMI), comorbidities and disease-related factors (dyspnea, FEV1, PaCO2 level, number of AECOPD/year) [7] [13] [21] [22] [23] [24]. In a systematic review of the literature, different predictive factors such: previous hospital admission, dyspnea, long term oral corticosteroids, using long term oxygen therapy, having low health status or poor health related quality of life and not having routine physical activity were all found to be significant risk factors of readmissions [2]. These results fit with our finding after multivariate analysis concerning dyspnea and past history of frequent exacerbations. But several other factors were identified in other studies. Bahadori et al. [25] identified preadmission oxygen use, history 
of lung infection, other chronic respiratory diseases, and shorter hospital stay as risk factors for readmission for AECOPD. Another review identified more severe COPD, older age, increased breathlessness, poor general condition, cyanosis, peripheral edema, impaired consciousness, poor coping at home, significant comorbidities, and failure to initial treatments as main factors for rehospitalization [26]. In the prospective observational study of Tsui et al:: previous non-invasive ventilation for AECOPD, high COPD Assessment Test (CAT) score, reduced 6-minute walk distance and a high number of admissions for AECOPD in the previous year were independently associated with time to first readmission. Subgroup analysis showed that anxiety was strongly associated with very frequent readmissions [12]. In our study, mMRC scale was used to appreciate symptoms instead of the CAT core since the retrospective type of the research. In a retrospective study carried out in Hong Kong [13], within1 year after discharge, $59 \%$ of COPD patients were readmitted at least once. Median time to first readmission after discharge was 240 days. The following factors were independently associated with shorter time to readmission: hospital admission within 1 year before index admission, total length of stay in index admission $>5$ days, nursing home residency, dependency in self-care activities, right heart strain pattern on electrocardiogram, on high dose inhaled corticosteroid and actual bicarbonate level $>25 \mathrm{mmol} / \mathrm{l}$. In the study of Lajas et al., independent predictors of high frequency of readmissions within 30 days after discharge were gender (male), exacerbator emphysema phenotype, occurrence of complications during admission, destabilized heart failure, and length of hospital stay [27]. A large retrospective, descriptive and epidemiological study was conducted using the Spanish National Hospital Database including COPD patients hospitalized for AECOPD between 2006 and 2012 in Spain. The risk of rehospitalization within 30 days of discharge for AECOPD was higher in patients aged 65 to 84 years, males, with comorbidities, malnutrition, not obese, respiratory acidosis, treated with NIV or discharged to health/social institutions [16].

In our study, frequent exacerbations were highly associated with multiples admissions. This is in accordance with several other reports [4] [18]. Santibanez et al. concluded in their study to the fact that a prior history of hospitalized exacerbations of COPD was associated with new admission for AECOPD with a statistically significant dose-response association. This effect was independent of COPD severity [18]. In another study, the main predictor of exacerbations requiring hospital admission was a past history of similar events (hospital admission for AECOPD the previous year). But contrary to Santibanez et al. results, the severity of the underlying COPD was an independent predictor of multiple admissions [28]. In the study of Guerrero et al., two or more prior AECOPD (OR, 2.47; 95\% CI, 1.51 - 4.05) was the only variable independently associated with 30-day readmission [29]. In the European COPD Audit, data of COPD exacerbation admissions was collected from 13 European countries. The 90 days readmission rate was $35 \%$ and was associated with previous admissions [30]. 
This may reflect the exacerbation susceptibility showed first in the Evaluation of COPD Longitudinally to Identify Predictive Surrogate Endpoints (ECLIPSE) study [31].

On another hand, we found that a low level of $\mathrm{PaO}_{2}$ is an independent factor associated to multiple admissions. In the study of Garcia-Aymerich et al., oxygen tension $(0.88,95 \%$ CI 0.79 to 0.98$)$ was one of the independent factors related to readmission in the final multivariate model. Other factors were also identified such: $>3$ admissions for COPD in the year before recruitment, low FEV1, reduced levels of usual physical activity and taking anticholinergic drugs [5]. In some studies, use of long-term home oxygen in COPD patients with chronic respiratory failure was independently associated with a shorter time to first readmission for AECOPD [2]. However in other studies, this association was not significant or it did not remain significant after adjustment [2]. Other abnormalities of gas exchange like an increased $\mathrm{PaCO}_{2}$ were significantly related to multiple admissions [13].

Additional studies are still necessary to identify other risk factors for AECOPD especially modifiable factors that are independently associated with a higher risk of readmission to the hospital. A standard definition of "readmission" in terms of delay and cause is necessary.

There is emerging scores predicting readmission for AECOPD like The Readmission After COPD Exacerbation (RACE) Scale [32], LACE index (length of stay, acuity of admission, co-morbidities, and emergency department visits within the last 6 months) [33], or The PEARL score (Previous admissions, the Extended MRC dyspnea score, Age, Right-sided heart failure and Left sided heart failure) [14]. These scores may guide readmission-reduction strategies by the identification of patients at high risk of readmission. The purpose is to implement evidence-based interventions. In fact, the identification of the risk factors highly associated with readmission rate would allow the implementation of a well defined post-discharge action plan for these patients.

Hence, some intervention components that reduce readmissions after AECOPD are currently proposed like adherence to recommendations [34], patient self-management, inhaler device training, pulmonary rehabilitation [35] [36], or telehealthcare [7].

Coping with this scope, some developed countries are now implementing programs to reduce readmissions for AECOPD after discharge tending to ameliorate care quality with better control of COPD's costs [37]. For example, in the United States, COPD is part of Medicare's Hospital Readmissions Reduction Program (HRRP) [7] [38] [39].

\section{Conclusion}

In summary, our results suggest that an $m M R C \geq 2$, a low $\mathrm{PaO}_{2}$ and frequent exacerbations are independently associated with multiple hospitalizations for AECOPD. The latter remain a challenging medical problem. Particular attention 
to such predictors may help identify a subgroup of COPD patients with a high risk of readmission in order to initiate specific readmission reduction programs.

\section{Conflicts of Interest}

The authors declare no conflicts of interest regarding the publication of this paper.

\section{References}

[1] Global Initiative for Chronic Obstructive Lung Disease (GOLD) (2019) Global Strategy for the Diagnosis, Management and Prevention of COPD.

http://www.goldcopd.org

[2] Bahadori, K. and FitzGerald, J.M. (2007) Risk Factors of Hospitalization and Readmission of Patients with COPD Exacerbation-Systematic Review. International Journal of Chronic Obstructive Pulmonary Disease, 2, 241-251. https://www.ncbi.nlm.nih.gov/pmc/articles/PMC2695199/pdf/copd-2-241.pdf

[3] Hurst, J.R., Donaldson, G.C., Quint, J.K., Goldring, J.J., Baghai-Ravary, R. and Wedzicha, J.A. (2009) Temporal Clustering of Exacerbations in Chronic Obstructive Pulmonary Disease. American Journal of Respiratory and Critical Care Medicine, 179, 369-374. https://doi.org/10.1164/rccm.200807-1067OC

[4] Wei, X., Ma, Z., Yu, N., Ren, J., Jin, C., Mi, J., Shi, M., Tian, L., Gao, Y. and Guo, Y. (2018) Risk Factors Predict Frequent Hospitalization in Patients with Acute Exacerbation of COPD. International Journal of Chronic Obstructive Pulmonary Disease, 13, 121-129. https://doi.org/10.2147/COPD.S152826

[5] Garcia-Aymerich, J., Farrero, E., Félez, M.A., Izquierdo, J., Marrades, R.M., Antó, J.M., et al. (2003) Risk Factors of Readmission to Hospital for a COPD Exacerbation: A Prospective Study. Thorax, 58, 100-105. https://doi.org/10.1136/thorax.58.2.100

[6] Gudmundsson, G., Gislason, T., Janson, C., et al. (2005) Risk Factors for Rehospitalisation in COPD: Role of Health Status, Anxiety and Depression. European Respiratory Journal, 26, 414-419. https://doi.org/10.1183/09031936.05.00078504

[7] Shah, T., Press, V.G., Huisingh-Scheetz, M. and White, S.R. (2016) COPD Readmissions: Addressing COPD in the Era of Value-Based Health Care. Chest, 150, 916-926. https://doi.org/10.1016/j.chest.2016.05.002

[8] Sharif, R., Parekh, T.M., Pierson, K.S., Kuo, Y.F. and Sharma, G. (2014) Predictors of Early Readmission among Patients 40 to 64 Years of Age Hospitalized for Chronic Obstructive Pulmonary Disease. Annals of the American Thoracic Society, 11, 685-694. https://doi.org/10.1513/AnnalsATS.201310-358OC

[9] Crisafulli, E., Ortega, S. and Torres, A. (2015) Predictors of Readmission in a Period of 30 Days or Less in Acute Exacerbation of Chronic Obstructive Pulmonary Disease. Clinical Pulmonary Medicine, 22, 172-176. https://doi.org/10.1371/journal.pone.0150737

[10] Prieto-Centurion, V., Markos, M.A., Ramey, N.I., Gussin, H.A., Nyenhuis, S.M., Joo, M.J., et al. (2014) Interventions to Reduce Rehospitalizations after Chronic Obstructive Pulmonary Disease Exacerbations. A Systematic Review. Annals of the American Thoracic Society, 11, 417-424. https://doi.org/10.1513/AnnalsATS.201308-254OC

[11] Shah, T., Churpek, M.M., Coca Perraillon, M. and Konetzka, R.T. (2015) Understanding Why Patients with COPD Get Readmitted: A Large National Study to De- 
lineate the Medicare Population for the Readmissions Penalty Expansion. Chest, 147, 1219-1226. https://doi.org/10.1378/chest.14-2181

[12] Tsui, M.S., Lun, F.C., Cheng, L.S., Cheung, A.P., Chan, V.L., Leung, W.S. and Chu, C.M. (2016) Risk Factors for Hospital Readmission for COPD after Implementation of the GOLD Guidelines. International Journal of Tuberculosis and Lung Disease, 20, 396-401. https://doi.org/10.5588/ijtld.15.0256

[13] Lau, A.C., Yam, L.Y. and Poon, E. (2001) Hospital Re-Admission in Patients with Acute Exacerbation of Chronic Obstructive Pulmonary Disease. Respiratory Medicine, 95, 876-884. https://doi.org/10.1053/rmed.2001.1180

[14] Echevarria, C., Steer, J., Heslop-Marshall, K., Stenton, S.C., Hickey, P.M., Hughes, R., et al. (2017) The PEARL Score Predicts 90-Day Readmission or Death after Hospitalisation for Acute Exacerbation of COPD. Thorax, 72, 686-693.

https://doi.org/10.1136/thoraxjnl-2016-209298

[15] Hijjawi, S.B., Abu Minshar, M. and Sharma, G. (2015) Chronic Obstructive Pulmonary Disease Exacerbation: A Single-Center Perspective on Hospital Readmissions. Postgraduate Medical, 127, 343-348.

https://doi.org/10.1080/00325481.2015.1015394

[16] Miguel-Díez, J., Jiménez-García, R., Hernández-Barrera, V., Carrasco-Garrido, P., Puente Maestu, L., Ramírez García, L., et al. (2016) Readmissions Following an Initial Hospitalization by COPD Exacerbation in Spain from 2006 to 2012. Respirology, 21, 489-496. https://doi.org/10.1111/resp.12705

[17] Groenewegen, K.H., Schols, A.M. and Wouters, E.F. (2003) Mortality and Mortality-Related Factors after Hospitalization for Acute Exacerbation of COPD. Chest, 124, 459-467. https://doi.org/10.1378/chest.124.2.459

[18] Santibáñez, M., Garrastazu, R., Ruiz-Nuñez, M., Helguera, J.M., Arenal, S., Bonnardeux, C., et al. (2016) Predictors of Hospitalized Exacerbations and Mortality in Chronic Obstructive Pulmonary Disease. PLoS ONE, 11, e0158727. https://doi.org/10.1371/journal.pone.0158727

[19] Jencks, S.F., Williams, M.V. and Coleman, E.A. (2009) Rehospitalizations among Patients in the Medicare Fee-for-Service Program. The New England Journal of Medicine, 360, 1418-1428. https://doi.org/10.1056/NEJMsa0803563

[20] Gorodeski, E.Z., Starling, R.C. and Blackstone, E.H. (2010) Are All Readmissions Bad Readmissions? The New England Journal of Medicine, 363, 297-298. https://doi.org/10.1056/NEJMc1001882

[21] Steer, J., Gibson, G.J. and Bourke, S.C. (2010) Predicting Outcomes Following Hospitalization for Acute Exacerbations of COPD. QJM, 103, 817-829. https://doi.org/10.1093/qjmed/hcq126

[22] McGhan, R., Radcliff, T., Fish, R., et al. (2007) Predictors of Rehospitalization and Death after a Severe Exacerbation of COPD. Chest, 132, 1748-1755.

https://doi.org/10.1378/chest.06-3018

[23] Kon, S.S., Jones, S.E., Schofield, S.J., et al. (2015) Gait Speed and Readmission Following Hospitalisation for Acute Exacerbations of COPD: A Prospective Study. Thorax, 70, 1131-1137. https://doi.org/10.1136/thoraxjnl-2015-207046

[24] Nastars, D.R., Rojas, J.D., Ottenbacher, K.J. and Graham, J.E. (2019) Race/Ethnicity and 30-Day Readmission Rates in Medicare Beneficiaries with COPD. Respiratory Care. https://doi.org/10.4187/respcare.06475

[25] Bahadori, K., FitzGerald, J.M., Levy, R.D., Fera, T. and Swiston, J. (2009) Risk Factors and Outcomes Associated with Chronic Obstructive Pulmonary Disease Ex- 
acerbations Requiring Hospitalization. Canadian Respiratory Journal, 16, e43-e49. https://doi.org/10.1155/2009/179263

[26] MacIntyre, N. and Huang, Y.C. (2008) Acute Exacerbations and Respiratory Failure in Chronic Obstructive Pulmonary Disease. Proceedings of the American Thoracic Society, 5, 530-535. https://doi.org/10.1513/pats.200707-088ET

[27] Cerezo Lajas, A., Gutiérrez González, E., Llorente Parrado, C., Puente Maestu, L. and de Miguel-Díez, J. (2018) Readmission Due to Exacerbation of COPD: Associated Factors. Lung, 196, 185-193. https://doi.org/10.1007/s00408-018-0093-y

[28] Müllerova, H., Maselli, D., Locantore, N., Vestbo, J., Hurst, J., Wedzicha, J., et al. (2015) Hospitalized Exacerbations of COPD, Risk Factors and Outcomes in the ECLIPSE Cohort. Chest, 147, 999-1007. https://doi.org/10.1378/chest.14-0655

[29] Guerrero, M., Crisafulli, E., Liapikou, A., Huerta, A., Gabarrús, A., Chetta, A., et al. (2016) Readmission for Acute Exacerbation within 30 Days of Discharge Is Associated with a Subsequent Progressive Increase in Mortality Risk in COPD Patients: A Long-Term Observational Study. PLoS ONE, 11, e0150737. https://doi.org/10.1371/journal.pone.0150737

[30] Hartl, S., Lopez-Campos, J.L., Pozo-Rodriguez, F., Castro-Acosta, A., Studnicka, M., Kaiser, B., et al. (2016) Risk of Death and Readmission of Hospital-Admitted COPD Exacerbations: European COPD Audit. European Respiratory Journal, 47, 113-121. https://doi.org/10.1183/13993003.01391-2014

[31] Hurst, J.R., Vestbo, J., Anzueto, A., Locantore, N., Mullerova, H., Tal-Singer, R., et al. (2010) Susceptibility to Exacerbation in Chronic Obstructive Pulmonary Disease. The New England Journal of Medicine, 363, 1128-1138. https://doi.org/10.1056/NEJMoa0909883

[32] Lau, C.S., Siracuse, B.L. and Chamberlain, R.S. (2017) Readmission after COPD Exacerbation Scale: Determining 30-Day Readmission Risk for COPD Patients. International Journal of Chronic Obstructive Pulmonary Disease, 12, 1891-1902. https://doi.org/10.2147/COPD.S136768

[33] Hakim, M.A., Garden, F.L., Jennings, M.D. and Dobler, C.C. (2018) Performance of the LACE Index to Predict 30-Day Hospital Readmissions in Patients with Chronic Obstructive Pulmonary Disease. Clinical Epidemiology, 10, 51-59. https://doi.org/10.2147/CLEP.S149574

[34] Seys, D., Bruyneel, L., Sermeus, W., Lodewijckx, C., Decramer, M., Deneckere, S., et al. (2018) Teamwork and Adherence to Recommendations Explain the Effect of a Care Pathway on Reduced 30-Day Readmission for Patients with a COPD Exacerbation. COPD, 15, 157-164. https://doi.org/10.1080/15412555.2018.1434137

[35] Spruit, M.A., Pitta, F., Garvey, C., et al. (2014) Differences in Content and Organisational Aspects of Pulmonary Rehabilitation Programmes. European Respiratory Journal, 43, 1326-1337. https://doi.org/10.1183/09031936.00145613

[36] Puhan, M.A., Gimeno-Santos, E., Scharplatz, M., et al. (2011) Pulmonary Rehabilitation Following Exacerbations of Chronic Obstructive Pulmonary Disease. Cochrane Database of Systematic Reviews, No. 10, CD005305. https://doi.org/10.1002/14651858.CD005305.pub3

[37] Aslam, S., Man, J., Behary, J., Riskallah, J., Ansary, S. and Kwan, B. (2016) Outcomes and Cost Effectiveness of a Respiratory Coordinated Care Program in $\mathrm{Pa}$ tients with Severe or Very Severe COPD. Open Journal of Respiratory Diseases, 6, 52-57. https://doi.org/10.4236/ojrd.2016.63008

[38] Goto, T., Faridi, M.K., Gibo, K., Toh, S., Hanania, N.A., Camargo, C.A., et al. (2017) Trends in 30-Day Readmission Rates after COPD Hospitalization, 2006-2012. Res- 
piratory Medicine, 130, 92-97. https://doi.org/10.1016/j.rmed.2017.07.058

[39] Jacobs, D.M., Noyes, K., Zhao, J., Gibson, W., Murphy, T.F., Sethi, S., et al. (2018) Early Hospital Readmissions after an Acute Exacerbation of Chronic Obstructive Pulmonary Disease in the Nationwide Readmissions Database. Annals of the American Thoracic Society, 15, 837-845. 